\title{
ВMJ Global Health Gender inequality in the global mental health research workforce: a research authorship scoping review and qualitative study in Nepal
}

\author{
Dristy Gurung (D) , ${ }^{1}$ Manaswi Sangraula (D) , ${ }^{2}$ Prasansa Subba (D) , \\ Anubhuti Poudyal (D) , ${ }^{3}$ Shelly Mishra, ${ }^{4}$ Brandon A Kohrt (D) ${ }^{4}$
}

\begin{abstract}
To cite: Gurung D, Sangraula M, Subba P, et al. Gender inequality in the global mental health research workforce: a research authorship scoping review and qualitative study in Nepal. BMJ Global Health 2021;6:e006146. doi:10.1136/ bmjgh-2021-006146
\end{abstract}

Handling editor Seye Abimbola

- Additional supplemental material is published online only. To view, please visit the journal online (http://dx.doi.org/10. 1136/bmjgh-2021-006146).

Received 29 April 2021 Accepted 9 November 2021

Check for updates

(C) Author(s) (or their employer(s)) 2021. Re-use permitted under CC BY-NC. No commercial re-use. See rights and permissions. Published by BMJ.

${ }^{1}$ Research Department, TP0 Nepal, Kathmandu, Nepal 2Department of Psychology, New School for Social Research, New York, New York, USA

${ }^{3}$ Department of Sociomedical Sciences, Columbia University, New York, New York, USA ${ }^{4}$ Division of Global Mental Health, The George Washington University School of Medicine and Health Sciences, Washington, District of Columbia, USA

Correspondence to Dristy Gurung;

dgurung@tponepal.org.np

\section{ABSTRACT}

Introduction Although women's health is prioritised in global research, few studies have identified structural barriers and strategies to promote female leadership and gender equality in the global health research workforce, especially in low-income and middle-income countries. Methods We conducted a mixed-methods study to evaluate gender equality in the mental health research workforce in Nepal. The scoping review assessed gender disparities in authorship of journal publications for Nepal mental health research, using databases (PsycINFO, PubMed, Web of Science, NepJol, NepMed) for 5 years. Qualitative interviews were conducted with 22 Nepali researchers to identify structural barriers limiting women's leadership.

Results Of 337 articles identified, $61 \%$ were by Nepali first authors. Among Nepali first authors, 38.3\% were women. Nepali women had half the odds of being first authors compared with men, when referenced against non-Nepali authors (OR $0.50,95 \% \mathrm{Cl} 1.30$ to 3.16 ). When limiting publications to those based on funded research, the odds were worse for first authorship among Nepali women (OR $0.37,95 \% \mathrm{Cl} 0.19$ to 0.71 ). The qualitative analysis supported the scoping review and identified a lack of gender-friendly organisational policies, difficulties in communication and mobility, and limited opportunities for networking as barriers to women's leadership in global health research.

Conclusion Efforts are needed for greater representation of Nepali women in global mental health research, which will require transformative organisational policies to foster female leadership. Those in leadership need to recognise gender inequalities and take necessary steps to address them. Funding agencies should prioritise supporting organisations with gender equality task forces, policies and indicators.

\section{INTRODUCTION}

There has been increased discourse among global health advocates for greater equity for women in health and in the workplace, as committed in United Nations' Sustainable Development Goal 5. ${ }^{1}$ Although global

\section{Key questions}

What is already known?

- Women in research face major structural barriers that hinder their career growth in global health research.

What are the new findings?

- Barriers and discrepancies in communication, mobility, gendered positions and work burden are even more prominent for female researchers in lowresource settings, such as Nepal. Current organisational policies are inadequate to address these barriers and a more nuanced approach is necessary to achieve gender equity in the workplace and in global health authorship.

What do the new findings imply?

- Current organisational policies are exploitative at worst and accommodating at best for women in Nepal. Transformative policies are needed to support female researchers' careers in Nepal.

health prioritises women's health interventions, there have been limited studies on the gender gap in the health research workforce, especially in low-income and middle-income countries (LMICs), ${ }^{2}$ where gender inequalities are greater than in high-income countries (HICs). ${ }^{34}$

Women in leadership roles leads to a 'ripple effect': it benefits women's recruitment and retention in the workforce as well as in the prioritisation of women's issues that have received less attention. ${ }^{4}$ However, very few women hold decision-making positions. The 2019 data suggest that women hold $70 \%$ of jobs in the health and social care workforce globally, but only hold $30 \%$ of the leadership positions. ${ }^{5}$ A gender composition analysis of the COVID-19 response task force from 87 countries also found that $85.2 \%$ of 
leadership and decision-making positions were held by men. ${ }^{6}$

Such a lack of gender-balanced representation in leadership can be seen in all phases of the global health programme cycle $^{7}$ : funding, design, implementation and evaluation. ${ }^{8}$ Authorship and publishing of global health research is also a gendered system where men are more likely to be first and last authors ${ }^{9}$ and women are less likely to be named authors in research publications, even if they made contributions to the publication. ${ }^{1011}$ Although women's representation as first and last authors is increasing, they still account for only onethird $(37 \%)$ of total publications. ${ }^{12}$ This has been further exacerbated by the COVID-19 pandemic, where the proportion of women in senior author roles has dropped below $30 \% .{ }^{13}$ Structural inequalities and barriers such as lack of women in leadership, and the additional burden of women's domestic and caregiving roles are some of the noted reasons behind the gender imbalance. ${ }^{13} 14$ These gendered stereotype within the patriarchal structure are reproduced and manifested at the workplace, which can further pose a challenge for women to advance their careers. ${ }^{15}$ Although several papers have highlighted the need for equity and diversity in authorship representation from LMICs and HICs, ${ }^{16}{ }^{17}$ few have raised concerns for inclusive practices of employment and remuneration in these global mental health research programmes, which may further perpetuate issues of gender inequality in LMICs. ${ }^{18}$

Nepali women continue to face challenges in everyday life: less household decision-making power, ${ }^{19} 20$ greater exposure to sexual violence, ${ }^{20}$ adverse reproductive healthcare outcomes, ${ }^{21}$ and less labour market participation. ${ }^{22}$ Because women face structural vulnerability in Nepal, they are also more likely to face disadvantages in the workplace. ${ }^{23}$ The gender wage gap remains high in Nepal: US\$2910 gross national income for women compared with US $\$ 4108$ for men,${ }^{24}$ with greater disparities for women of lower castes and those living in rural areas. ${ }^{25}$ The national literacy rate in 2018 was $59.7 \%$ for women compared with $78.6 \%$ for men ${ }^{25}$ and only $13.2 \%$ of managerial positions are held by women in Nepal. ${ }^{26}$ Societal expectations to fulfil traditional gender roles (eg, marriage and having children) coupled with the lack of gender-sensitive policies in the workplace continue to hamper Nepali women's professional opportunities and compensation. ${ }^{27}$ Because challenges in gender equity are also common in many LMICs, ${ }^{28}$ general findings from Nepal may be applicable to other LMIC settings.

In this paper, we use a mixed-methods approach in which we first aim to understand the status of women's leadership in academic productivity in global mental health research in Nepal by conducting a scoping review of published peer-reviewed papers and comparing the number of publications by Nepali authors who are women, as well as Nepali women's representation as senior authors. Second, we employ qualitative methods to explore the structural barriers and discrimination faced by women who have worked in Nepal's mental health research, and we document their strategies to overcome these barriers.

\section{METHODS}

\section{Scoping review methodology}

The first component of the study was a scoping review to determine representation of Nepali women as first and senior authors. The review followed the five steps of scoping methodology: (1) identifying the research question; (2) identifying relevant literature; (3) article selection; (4) data charting and; (5) collating, summarising, and reporting results. ${ }^{29}$ We first identified published peer-reviewed journal articles on mental health in Nepal dated 2015-2020 using keywords and search terms in international journal databases (PubMed, PsycINFO, Web of Science) and Nepal national research databases (NepMed, NepJol) (see online supplemental material 1 for search terms and inclusion criteria). The scoping review was registered in Open Science Framework (date: 28 June 2020, registration doi:10.17605/OSF.IO/ J8FHA). The preferred Reporting Items for Systematic Reviews and Meta-Analyses (PRISMA)-Scoping Reviews (ScR) checklist for scoping reviews is included in online supplemental material 5).

\section{Screening, extraction and analysis}

Three researchers (SM, AP and DG) used keywords across five databases and uploaded the articles from PubMed, PsycINFO and Web of Science on Covidence, whereas articles from Nepali databases (NepMed and NepJol) were downloaded in Excel for screening because they were unable to be uploaded in Covidence. SM, AP and DG screened the titles and abstracts for inclusion based on our criteria, followed by a detailed abstract and fulltext review. Any discrepancy was discussed and resolved by a senior researcher (BAK). SM, AP, DG and MS then coded the articles in an extraction sheet, which recorded information on gender and ethnicity of first, last and corresponding authors, funding type, study type, journal of publication, list of authors, ethnicity and gender.

To determine caste/ethnicity among Nepali authors, researchers of Nepali origin (DG, MS, AP and PS) identified ethnicity by surname because caste/ethnicity in Nepal is typically indicated by last name. Though determining gender without self-report methods risks inaccuracies, we followed the practice of coding gender by first name in authorship lists, which is standard practice in other studies which have analysed authorship representation. ${ }^{89}$ Because of the limited information available from authorship name lists, we have limited the use of 'gender' to the terms 'women' and 'men', while acknowledging this will not accurately capture all authors' gender identities.

To identify patterns of difference in authorship, we conducted within group comparisons for one sample binomial comparisons for gender biases within the 
specific group (ie, Nepali and non-Nepali authored publications are analysed separately). Significant results demonstrate a deviation from $50 \%$ split by gender. In addition, between group comparisons are MantelHaenszel ORs with 95\% CIs. Odds represent the ratio of the odds of an event in one demographic group compared with the odds of an event in a comparison demographic group, for example, women's authorship compared to men's authorship among Nepalis referenced against the ratio for non-Nepali authors based on gender. Analyses were conducted using SPSS Statistics V.27.0. ${ }^{30}$

\section{Qualitative methodology Participants}

Authors recruited participants by compiling a list of professionals who had experience working in global mental health research and with varying years of experience. Persons that added diversity to the sample in terms of academic background, age, type of institution and work experience were added to the list. For the qualitative component, all participants self-reported their gender identity. Authors prioritised interviewing women to collect data on their work experiences but also interviewed a smaller sample of men to gather their perspectives. Exclusion criteria were persons providing only clinical care and not conducting health research, and persons who did not self-identify as of 'Nepali origin' We checked for data saturation after every interview and stopped conducting new interviews when the saturation point was reached. Participants were initially contacted via phone or email. After confirming initial interest in the research, interviewers met with participants and conducted face-to-face interviews.

\section{Data collection}

Interviews lasted 30-75 min and were conducted by researchers DG, MS and PS. Detailed field notes were also recorded on structured reflection sheets. Interview guides were developed to be unbiased with openended and neutral questions and were also pilot tested to address potential biases as well as the best methods to probe about sensitive personal experiences. At least two interviewers were present during each interview to hold each other accountable to remain neutral. All interviews were conducted in neutral (eg, not their workplaces) and safe spaces. All interviews were conducted in Nepali and were audio recorded. All interviewers (DG, MS and PS) were employed by the same mental health organisation (Transcultural Psychosocial Organization Nepal) and identified as having Nepali origin. Interviewees were asked about their experiences working in health research, barriers to gaining leadership (such as through promotions and publications), their understanding of why such difficulties occurred, and potential strategies to mitigate these barriers.

\section{Data analysis}

Interviews were translated from Nepali audio recordings into English. We used an exploratory-descriptive level of qualitative analysis. ${ }^{31}$ Parent and child codes were created by the authors after initially reviewing interview guides, transcripts and field notes. The coders (DG, MS and PS) brought extensive training and experience to conducting and analysing qualitative data, and the team used an iterative process to apply the initial codes to the transcripts, review and revisions to codes until a final codebook with definitions, inclusion and exclusion criteria was developed. After several rounds of interrater reliability (IRR) testing, coders finalised an IRR score of 0.78 before coding all transcripts in NVivo. ${ }^{16} 3233$ While coding the transcripts, coders met regularly to discuss further clarifications in the codebook, observations and challenges. See attached Consolidated Criteria for Reporting Qualitative Research (COREQ) Checklist (online supplemental material 4) for details on the quality of the qualitative research methods. Data were analysed using the "what matters most' framework, which has previously been used to understand structural discrimination in several populations including mental health problems among Chinese immigrants. ${ }^{34}$ In the data analysis process, the researchers identified 'what matters most' to women working in research, 'what matters most' to organisations they are working in, and the discrepancies in these values.

\section{RESULTS}

\section{Scoping review}

A total of 1413 articles were identified after the keyword search across five databases from the period of 1 January 2015-31 December 2019 in PubMed ( $\mathrm{n}=506)$, PsycINFO $(\mathrm{n}=268)$, Web of Science $(\mathrm{n}=366)$, NepJol $(\mathrm{n}=163)$, NepMed $(n=110)$. After removing duplicates $(n=446)$, there were 967 articles identified for title and abstract screening. We removed 453 articles because they did not meet our inclusion criteria. A detailed title, authorship and abstract review was done for 514 articles. A total of 177 articles were removed because they did not meet the inclusion criteria after detailed review. A total of 337 articles met the inclusion criteria (see online supplemental material 2-PRISMA diagram).

Table 1 and figure 1 summarise the authorship in mental health publications in Nepal over the past 5 years. Of 337 journal publications, $61.1 \%$ were by Nepali first authors. Among Nepali first authors, $38.3 \%$ were women. This gender disparity was not observed among nonNepali first authors among whom, $55.7 \%$ were women, the majority of whom were from the USA $(17.5 \%)$ and UK $(10.7 \%)$. The proportion of Nepali female first authorship decreased to $35 \%$ when including only international journals, and further decreased to $30.4 \%$ for funded research publications. Among senior authors, the gender disparity was comparable for both Nepali authorship (27.3\% women) and non-Nepali authorship (33.0\% 
Table 1 Authorship in mental health research Journal publications from 1 January 2015 to 31 December 2019 ( $n=337)$ compared by gender and nationality

\begin{tabular}{|c|c|c|c|c|c|}
\hline $\begin{array}{l}\text { Authorship and } \\
\text { publication type }\end{array}$ & Group* & Men, n (\%) & Women, n (\%) & $\begin{array}{l}\text { Gender within } \\
\text { nationality } \\
\text { comparison } \dagger\end{array}$ & $\begin{array}{l}\text { Gender between } \\
\text { nationality } \\
\text { comparison } \ddagger\end{array}$ \\
\hline \multirow{2}{*}{$\begin{array}{l}\text { First authorship, all } \\
\text { publications }(n=337)\end{array}$} & Nepali & $127(61.7)$ & 79 (38.3) & $\mathrm{T}=3.28, p=0.001$ & \multirow[t]{2}{*}{$\mathrm{OR}=0.50(0.32$ to 0.77$)$} \\
\hline & Non-Nepali & $58(44.3)$ & $73(55.7)$ & $\mathrm{T}=-1.22, \mathrm{p}=0.221$ & \\
\hline \multirow{2}{*}{$\begin{array}{l}\text { First authorship, } \\
\text { international journals§ } \\
(n=263)\end{array}$} & Nepali & $87(64.4)$ & $48(35.6)$ & $\mathrm{T}=3.27, \mathrm{p}=0.001$ & \multirow[t]{2}{*}{$\mathrm{OR}=0.43(0.26$ to 0.70$)$} \\
\hline & Non-Nepali & $56(43.8)$ & $72(56.3)$ & $\mathrm{T}=-1.32, \mathrm{p}=0.19$ & \\
\hline \multirow{2}{*}{$\begin{array}{l}\text { First authorship, funded } \\
\text { research } \emptyset(n=159)\end{array}$} & Nepali & $48(69.6)$ & $21(30.4)$ & $\mathrm{T}=3.13, \mathrm{p}=0.002$ & \multirow[t]{2}{*}{$\mathrm{OR}=0.37(0.19$ to 0.71$)$} \\
\hline & Non-Nepali & $41(45.6)$ & $49(54.4)$ & $\mathrm{T}=-0.74, \mathrm{p}=0.46$ & \\
\hline \multirow{2}{*}{$\begin{array}{l}\text { Senior** authorship, all } \\
\text { publications }(n=337)\end{array}$} & Nepali & 93 (72.7) & 35 (27.3) & $T=5.85, p<0.001$ & \multirow[t]{2}{*}{$\mathrm{OR}=0.76(0.47$ to 1.25$)$} \\
\hline & Non-Nepali & $128(67.0)$ & $63(33.0)$ & $T=3.55, p<0.001$ & \\
\hline \multirow{2}{*}{$\begin{array}{l}\text { Senior }{ }^{\star \star} \text { authorship, } \\
\text { international journals§ } \\
(n=263)\end{array}$} & Nepali & $53(75.7)$ & 17 (24.3) & $T=5.35, p<0.001$ & \multirow[t]{2}{*}{$\mathrm{OR}=0.67(0.36$ to 1.25$)$} \\
\hline & Non-Nepali & $125(67.6)$ & $60(32.4)$ & $T=5.59, p=0.001$ & \\
\hline \multirow{2}{*}{$\begin{array}{l}\text { Senior }{ }^{*} \text { authorship, } \\
\text { funded research } \emptyset \\
\text { ( } n=159)\end{array}$} & Nepali & $21(75.0)$ & $7(25.0)$ & $\mathrm{T}=3.42, \mathrm{p}=0.001$ & \multirow[t]{2}{*}{$\mathrm{OR}=0.83(0.32$ to 2.13$)$} \\
\hline & Non-Nepali & $92(71.3)$ & $37(28.7)$ & $\mathrm{T}=4.11, \mathrm{p}<0.001$ & \\
\hline
\end{tabular}

*Group refers to Nepali descent, whether Nepali nationality or non-resident Nepali living outside the country. Non-Nepali authors include American, Dutch, Norwegian and other academics conducting research in Nepal.

†Within group comparisons are one sample binomial comparisons for gender biases within the specific group (ie, Nepali and non-Nepali authored publications are analysed separately). Significant results demonstrate a deviation from $50 \%$ split by gender.

¥Between group comparisons are Mantel-Haenszel ORs with $95 \% \mathrm{Cl}$. Odds represent the ratio of the odds of women’s authorship compared with men's authorship among Nepalis referenced against the ratio for non-Nepali authors based on gender.

§International journals are defined as any journal published outside of Nepal, including non-Nepali regional journals from Asia.

ףFunded research refers to journal publications where a funder was identified, such as the Wellcome Trust, the US National Institutes of

Health, foundations and university grants.

${ }^{\star *}$ Senior author is the last author unless otherwise specified in the publication.

women), that is, Nepali, USA, UK and other senior authors were more likely to be men.

When Nepali men were senior authors, only $37.5 \%$ of the first authors were women. In contrast, when Nepali women were senior authors, $62.9 \%$ of the first authors were women, demonstrating nearly three times greater odds of female first authorship when the senior author was a Nepali woman (OR 2.80, 95\% CI 1.26 6.26, $\mathrm{p}=0.012)$.

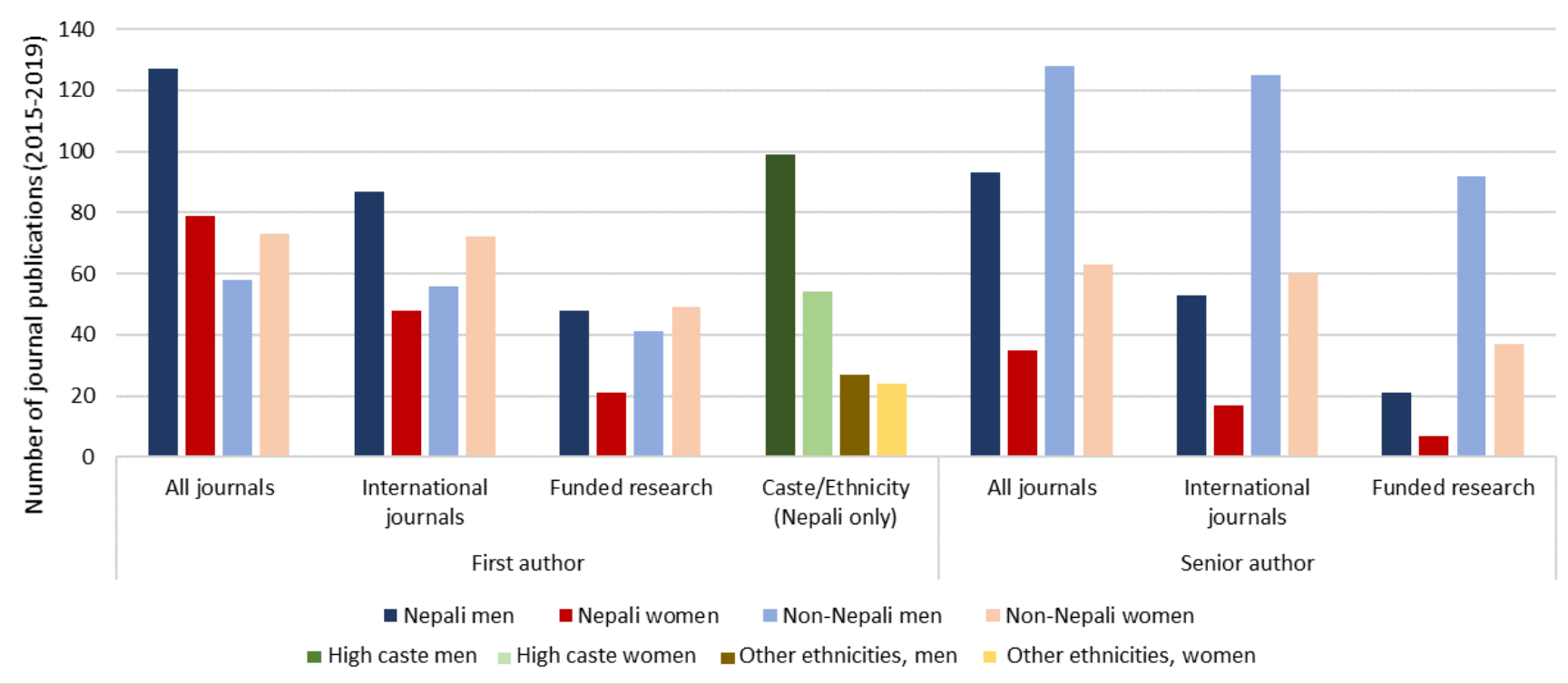

Figure 1 Authorship of Nepal mental health research in journal publications from 1 January 2015 to 31 December 2019 $(n=337)$ 


\begin{tabular}{|c|c|}
\hline Participant characteristics & $\mathbf{N}(\%)$ \\
\hline \multicolumn{2}{|l|}{ Gender } \\
\hline Men & $7(30.4)$ \\
\hline Women & $16(69.6)$ \\
\hline \multicolumn{2}{|l|}{ Caste/ethnicity } \\
\hline $\begin{array}{l}\text { Brahman/Chhetri (historically considered } \\
\text { upper caste groups) }\end{array}$ & $17(73.9)$ \\
\hline $\begin{array}{l}\text { Dalit (historically considered lower caste } \\
\text { groups) }\end{array}$ & $1(4.3)$ \\
\hline Newar (ethnic minority group) & $3(13.1)$ \\
\hline $\begin{array}{l}\text { Janajati (historically marginalised ethnic } \\
\text { minority groups) }\end{array}$ & $2(8.7)$ \\
\hline \multicolumn{2}{|l|}{ Current workplace institutions } \\
\hline Non-governmental organisation & $8(34.8)$ \\
\hline $\begin{array}{l}\text { International non-governmental } \\
\text { organisation }\end{array}$ & $6(26.1)$ \\
\hline Government organisation & $5(21.7)$ \\
\hline Academic institution & $3(13.1)$ \\
\hline Other workplace & $1(4.3)$ \\
\hline \multicolumn{2}{|l|}{ Years of experience in research } \\
\hline 3 months to 2 years & $5(21.7)$ \\
\hline $3-6$ years & $9(39.2)$ \\
\hline $7-10$ years & $5(21.7)$ \\
\hline $11-20$ years & $3(13.1)$ \\
\hline$>20$ years & $1(4.3)$ \\
\hline \multicolumn{2}{|l|}{ Educational qualification } \\
\hline Master's degree (MA, MPH, MSc, MPhil) & $17(73.9)$ \\
\hline Medical degree (MD) & $2(8.7)$ \\
\hline $\mathrm{PhD}$ & $4(17.4)$ \\
\hline
\end{tabular}

When non-Nepali men were senior authors, only $39.1 \%$ of the first authors were women, which is comparable to the findings with Nepali male senior authors. When nonNepali women were senior authors, $52.4 \%$ of the first authors were women. However, there was no statistical evidence of an association in the odds of having a female first author given a non-Nepali female senior author (OR $1.71,95 \%$ CI $0.93,31.15, \mathrm{p}=0.082$ ).

High-caste Hindu groups (Brahman/Chhetri) comprised $75.0 \%$ of the Nepali first-authored publications. Among high-caste Hindu first authors, only $35.3 \%$ were women, which represents a statistically significant gender disparity among high-caste Hindus ( $\mathrm{T}=6.19, \mathrm{p}<0.001)$. In contrast, for the other ethnic and caste groups (Janajati ethnic minorities and lower caste Hindu groups) there were no gender differences: women comprised $47.1 \%$ of the first authorship positions ( $\mathrm{T}=-0.28, \mathrm{p}=0.78)$.

\section{Qualitative interviews}

Table 2 provides the demographic characteristics of the respondents and table 3 summarises the findings from the interviews. Three major themes were identified from our qualitative interviews: organisational structures, barriers and mitigating strategies. Online supplemental material 3 includes direct quotes from participants under each of the domains discussed below.

\section{Organisational structures}

Participants across varying institutions reported similar patterns in organisational structure and workplace policies. Most participants noted that their organisations employed more women than men, but women's positions were often limited to assistant-level staff while those in decision-making positions were predominantly men. Because many women are employed in the public health sector, some male participants characterised these organisations as gender inclusive. Women pointed out that gender equity is beyond gender representation. They mentioned that opportunities, such as furthering education or receiving grants to conduct research projects, are often only accessible to those with decision-making power. Women shared that they were tokenised and often felt unheard by leaders in the decision-making process.

In terms of organisational policies, gender sensitive policies such as sexual harassment and time flexibility were mostly reported by participants from international non-government organisations (INGOs) and not from Nepali institutions. Participants from non-governmental organisations (NGOs) and government organisations cited maternity leave and quotas as gender sensitive policies. Early-career participants were unaware of organisational gender-sensitive policies and mentioned that they did not receive an overview of them. Gender Equality and Social Inclusion policies were discussed across organisations. However, participants, mainly from government organisations, stressed that even if there are gender sensitive policies, they are rarely implemented.

If we look at the entry level...there are quotas for men and women, quotas for Dalit [lower caste Hindu groups] and Janajati [ethnic minority groups], so the gender is balanced [at entry level]. However, there isn't such a system... to ensure balance in higher positions. (Male, Government employee)

\section{Barriers}

\section{Mobility}

Participants mentioned challenges with transportation, security, socio-cultural norms, and stigma, that reduced their mobility in project implementation and research sites. For example, organisations often provide motorbikes as transportation for their staff but women in Nepal rarely have experience driving them. A participant mentioned that scooters, which more women have licenses for, are often not provided.

Many female participants cited safety and security as a challenge when travelling for work, such as walking in secluded areas. Participants also mentioned other sociocultural norms and values that restricted their mobility to rural areas, such as not being able to leave their 
Table 3 Summary of structural barriers, what matters most to women and organisations, and mitigation strategies

\begin{tabular}{|c|c|c|c|}
\hline Structural barriers & $\begin{array}{l}\text { What matters most for } \\
\text { women }\end{array}$ & $\begin{array}{l}\text { What matters most for } \\
\text { organisation leaders }\end{array}$ & Mitigating strategies \\
\hline \multicolumn{4}{|l|}{ Mobility } \\
\hline $\begin{array}{l}\text { Lack of safety and } \\
\text { security while travelling } \\
\text { Stigma of travelling } \\
\text { with men and living } \\
\text { separately from family }\end{array}$ & $\begin{array}{l}\text { Safety, security and social } \\
\text { acceptance while travelling } \\
\text { for work } \\
\text { Fulfilling family expectations } \\
\text { and societal norms }\end{array}$ & $\begin{array}{l}\text { Staff can meet the frequent } \\
\text { travel demands of the job }\end{array}$ & $\begin{array}{l}\text { Female staff able to travel in groups or } \\
\text { in pairs } \\
\text { Organisations ensure safe transport } \\
\text { mechanisms } \\
\text { Gender-friendly policy }\end{array}$ \\
\hline
\end{tabular}

Family roles and

responsibilities

restricting mobility

Effective communication and networking

Lack of understanding Clearer understanding of about harassment and abuse, and reporting process

Social norms restricting women to raise harassment, abuse and the reporting process Clear mechanisms to raise grievances and fair or structured salary and grievances, negotiate, or incentive policies speak against authority Environment to build rapport Challenges in networking and network without going due to social restrictions against societal norms
Staff who can build good rapport with relevant stakeholders, donors, project beneficiaries, research participants and government officials for smooth implementation of

the project
System to deal with harassment and protect dignity

Clear communication of organisational policies, confidentiality policies and grievance handling processes (through orientation or training)

Capacity building and empowerment through training relating to communication skills and negotiation skills.

Practice strategic assertiveness networking opportunities

Female role models: women in leadership positions within the organisation can inspire other women to be better advocates

Establishing women's networks

\section{Work burden and productivity}

\section{Multiple roles and} responsibilitiesprofessional as well as primary caretaker in the family

Safety and social restrictions limiting women's time contribution

Unfair and inadequate leave and structural policies and organisational expectations

\section{Being able to fulfil \\ Staff are able to complete} professional as well as family roles and responsibilities without being penalised Organisation's structure and policies facilitate women's productivity and career growth the tasks efficiently on time to meet the deadlines of donors and other stakeholders

\section{Gender-sensitive policy}

Gender equality mechanisms (dismantle or redefine the definition of the 'ideal worker')

Conducive work environment (familyfriendly workplaces; equal parental leave)

Time flexibility

Destigmatising parenting roles

\section{Gendered positions and role}

\begin{tabular}{|c|c|c|c|}
\hline $\begin{array}{l}\text { Biased view that } \\
\text { women's personal traits } \\
\text { do not fit leadership } \\
\text { positions } \\
\text { Disregarding female } \\
\text { authority or leadership } \\
\text { Assigning positions and } \\
\text { roles based on gender- } \\
\text { biased views }\end{array}$ & $\begin{array}{l}\text { Being able to apply to } \\
\text { any positions without } \\
\text { discrimination based on their } \\
\text { gendered expectations } \\
\text { Roles and authority being } \\
\text { respected }\end{array}$ & $\begin{array}{l}\text { Those in leadership } \\
\text { positions can deal with } \\
\text { government officials } \\
\text { and other stakeholders } \\
\text { confidently, can handle } \\
\text { challenging situations, and } \\
\text { can fulfil the positions and } \\
\text { roles assigned to them } \\
\text { effectively }\end{array}$ & $\begin{array}{l}\text { Supportive female role models in } \\
\text { leadership positions } \\
\text { Gender analysis of organisational } \\
\text { systems and diversity management } \\
\text { Affirmative action and gender-equitable } \\
\text { recruitment, promotion, career } \\
\text { advancement and retention }\end{array}$ \\
\hline
\end{tabular}


family, husband and children behind. Participants also mentioned the stigma placed on women for travelling alone, with male colleagues or staying overnight in unfamiliar places.

\begin{abstract}
It's acceptable for my parents if I take a room anywhere. But if my sister did the same then my parents would be worried about her whereabouts. People in our society think that women of reproductive age are vulnerable... Such problems create obstacles in mobility. Organizations also demand frequent travelling, and they ask women if they are willing to take the job or not, or if they have any kids or not. In many places, they try to recruit women under 25, for the front desk job. (Male, NGO employee)
\end{abstract}

Although considerations related to safety, security, and meeting family obligations were cited as important for women, what mattered most for organisations was to hire staff who were able to meet the frequent travel demands of the job. Therefore, participants mentioned that their organisations often offered women jobs that do not require travel, without exploring options to ease mobility challenges. Participants reported that women are left with the option of either challenging social norms by travelling independently around the country vs only fulfilling tasks that do not require mobility, thus limiting their career opportunities.

\section{Effective communication and networking}

Study participants highlighted that women in Nepal are often raised to be complacent and amiable. This makes it challenging for women to identify and communicate effectively, develop a professional network and to negotiate salary and other incentives. Most of the female participants stated that they had not experienced sexual harassment at work but had colleagues with such experiences. However, female participants faced emotional and verbal abuse, but were not certain if this was considered harassment. Participants mentioned that because Nepali culture does not normalise open discussions about sex, identifying sexual innuendos or sexual harassment, and communication about these issues becomes a challenge. Participants were often unaware of harassment policies and how to report it. Because of this systemic barrier, female participants noted that they often communicated their difficulties to other women in the organisation but not formally to the decision makers.

Participants agreed that effective communication was key for salary negotiations, building rapport with government officials and stakeholders, and claiming authorship positions. Female participants expressed that, in Nepali culture, men are taught to express their opinions and 'fight for it', whereas non-agreeable women are less accepted in society, especially in the workplace, which makes it difficult for women to push for a higher salary. Female participants expressed that it is difficult to be taken seriously by government officials and community leaders who are typically men, and the women said they often get sidelined by their male colleagues:
Even if the male researcher is a new guy from a non-research background people in the community would listen more to him and completely disregard what I say. [They] address him as 'Sir,' and call me 'Sister.' It has happened to me so many times. (Female, INGO employee)

Participants explained that close social interactions are necessary to build effective working relationships with government officials but these interactions are often deemed 'culturally unfit' for a woman.

It works better when you can engage in an informal gathering, go out to dinner and all... And if women have to be engaged in such things with government officials, or with some male colleagues, then they would feel it's culturally inappropriate and difficult at the same time... When you aren't part of these activities then you tend to be sidelined. (Female, INGO employee)

\section{Work burden and productivity}

Because of limited funding from donors and short project cycles, participants described their work in academics and research as competitive. I/NGOs, government organisations, and academic institutions have limited available positions in Nepal, which leads to pressure to excel at the job. However, this is a challenge for women, who often have to balance multiple roles and familial responsibilities outside the workplace.

\section{Women are working competitively in the organization and looking out for their families. They work three times more than men and it is a lot of burden. And there is a dilemma for them to set their priorities between work, home and oneself. We have to struggle with the time... We prioritize others more than ourselves, so that might have created barriers for progress. (Female, NGO em- ployee)}

Inflexible work hours were another challenge. Participants gave examples of pay cuts for late arrival while having to work late to meet donor deadlines. A male NGO employee shared that he could stay late in the office to meet deadlines only because he is a man and the same could not be expected from female staff. In most families, women are expected to be home by early evening and often have difficulty finding safe transportation at later hours of the evening. On the contrary, a female participant shared that her organisation is led by women who have children and, therefore, is accommodating to their office hours and roles outside of work.

Although 3-month maternity leave was often cited as an example of a policy that supports women's career growth, many participants also shared that this was not enough. Participants reported that organisations preferred not to hire newly married or pregnant women because they would have to provide maternity leave. The participants thus described flexibility in working hours, being able to take leave without a hassle, and considerations of other roles and responsibilities while setting work deadlines as what mattered most to them. 


\section{Gendered positions and roles}

Societal and organisational bias towards gender roles was noted as another key barrier to professional growth. Participants shared that positions such as managers, board members, faculty leads, advisors and permanent staff were mostly held by men in their organisations. Similarly, technical roles, such as statisticians or research managers, were occupied by men while caregiving roles, such as counsellors or psychologists, were said to be occupied by women. Many participants also highlighted that staff were often selected based on their preconceived gender roles. For example, women were often seen as efficient, easy-going, and non-questioning of leaders, making them a fit for entry-level positions. However, for higher or leadership positions, women were seen as less proactive in nature.

\begin{abstract}
Most of the time, men take the lead. But they hire women, whenever they need to execute easy tasks, assuming that women readily obey commands. For example, they prefer women for intern and data entry positions. And, they prefer men in field coordinator positions. (Female, NGO employee)
\end{abstract}

Participants revealed that Nepali culture and society groomed men to be confident and women to be compliant. Even if women were in leadership positions, their authority was often disregarded. Participants reported that these gendered positions based on stereotyped views of women's nature and skills make them hesitant to apply for certain positions and, even if they do, they have difficulty being hired. A male participant acknowledged this issue: women have to 'be rebellious to become a leader' or work harder than male colleagues to get the same role.

\section{Mitigating strategies}

Some of the mitigating strategies suggested by the participants included gender-sensitive organisational policies, support for female role models in the workplace, women's support networks, tailored networking and mentorship opportunities for female employees. Participants suggested that gender-sensitive policies should go beyond sexual harassment policies and should also encompass equitable opportunities for all staff. Maternity leave, day care support, flexible work hours and work from home options were some of the gendersensitive policies important for female productivity at the workplace. Recognition of the challenges that women face when travelling and providing safety and security, such as provision of vehicles and proper accommodations, instead of not hiring women for certain positions or limiting travel opportunities, was another important mitigation strategy. Participants also suggested that the organisation clearly communicate their harassment policies so that all the employees know about them.

Participants noted that effective implementation of existing gender sensitive policies is integral. Creating a comfortable work environment and a mechanism for women to report harassment anonymously is important. Therefore, responsible and anonymous handling of grievances was an important strategy to ensure a genderequitable work environment.

Women should feel safe sharing their problems, and our goal should be that we should not limit their voice and perception...in most of the cases, men don't understand women's problems. Thus, we can create a safe space for women where we could all share our problems...we can create a channel from where we can circulate our [women's] messages to all [staff]. (Female, INGO employee)

Participants also mentioned that gender sensitivity should go beyond policies. It was suggested that male colleagues should take the responsibility to be inclusive of their female colleagues when networking with government officials and community leaders. This includes not conducting meetings at inopportune times, clearly introducing staff and their position to stakeholders, and creating space for female colleagues to discuss their opinions during meetings. For professional development, participants emphasised the need for supportive female role models in decision-making positions and tailored networking opportunities for female employees. Although respondents had experience discussing gender issues with their male supervisors, they believed that a female supervisor might be more inclined to empathise with the female employees' problems and advocate for gender-sensitive policies.

\section{DISCUSSION}

Our scoping review demonstrated that first authors were high-caste Nepali men, whereas senior authors were nonNepali men, especially for funded research. The qualitative study highlighted structural challenges and nuances behind the disparity in authorship and leaderships in mental health research sector. The interviews revealed various structural barriers for women to attain leadership roles, such as lack of female role models, lack of gendersensitive organisational policies to support female leadership along with inadequate implementation of existing policies, limited opportunities for networking, and a clash between personal, family and organisational expectations. This is reflected in the authorship positions of women in the scoping review, with a similar lack of women in key authorship positions in other global health research. $^{13}$

Our analysis using a 'what matters most' framework highlighted the discrepancies in the expectations of women researchers versus organisational leadership. What mattered to the organisation leaders was staff who were able to build good rapport with relevant stakeholders, donors, project beneficiaries, and government officials for smooth implementation. This was prioritised by leadership as an important skill for career progression, while not accounting for the structural and cultural barriers against women to participate in these communication avenues. Although organisation leaders preferred 


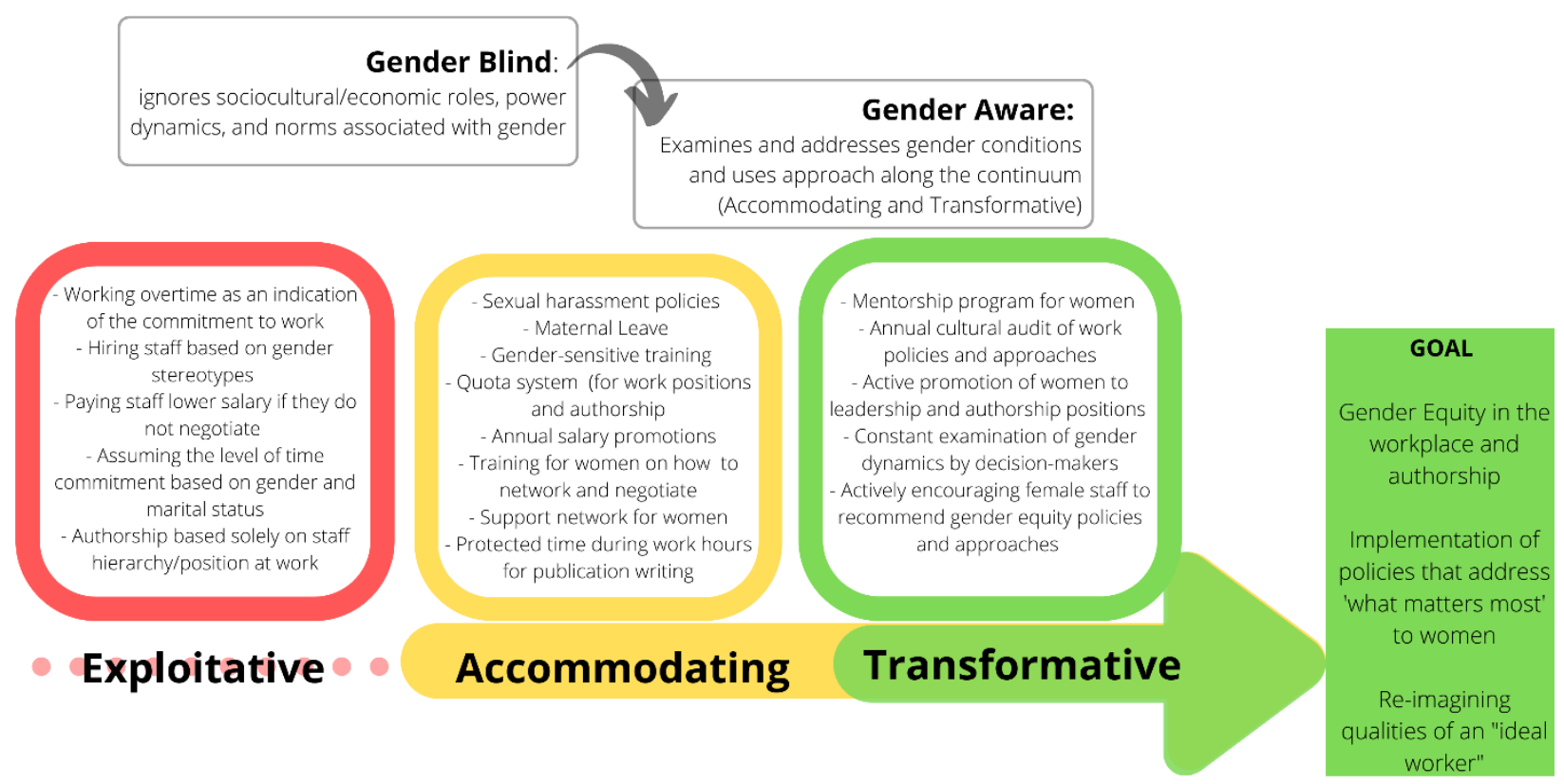

Figure 2 Adaptation of characteristics of the gender integration continuum based on findings in Nepal.

employees who were efficient and productive, female staff had competing interests at home and work, which did not fit the stereotypical expectation for an ideal worker'. ${ }^{35}$ What matters most to organisation leadership may stem from the social and cultural norms and their expectations may be reflective of the wider social structure, as institutions are an extension of such community and culture. ${ }^{34}$

Strategies to reflect and adjust discriminative or exploitative policies to transformative policies may help organisations achieve gender equity in leadership positions and authorship. We use the Gender Integration Continuum ${ }^{36}$ (figure 2) to highlight the structural barriers identified in our study and to recommend possible strategies based study participants' experiences and findings from literature. Study participants stated that although their organisations had some gender-sensitive policies surrounding maternity leave, salary promotions and sexual harassment, they also practised exploitative implementation processes where only those who aggressively negotiate are provided with benefits of increased salary or leave. Although some negotiations are better than strict no-negotiation policies, when negotiations are feasible and practised mostly by male employees, this may lead to exploitative process that institutions must acknowledge and amend. ${ }^{37}$ Though often unintentional, these approaches are categorised as exploitative according to the Gender Integration Continuum because they reinforce gender inequalities and do not address the sociocultural barriers and gender norms that prevent equal access to supportive policies. ${ }^{36}$

A majority of participants suggested accommodating policies such as establishing a support network for women and providing trainings for women on communication and negotiation skills. While these approaches are helpful and necessary, the gender integration continuum suggests that they may not be transformative as they do not attempt to address the gender systems that cause the differences and inequalities. ${ }^{36}$ Gender-transformative approaches such as normalising supportive conversations on gender while fostering an enabling workplace environment, annual gender auditing to identify gaps in policies and practices, and active promotion of women for authorship and leadership positions, ${ }^{39}$ were not suggested by our study participants. This may be because there are few examples of gender-transformative approaches known by the participants within local organisations.

Gender-transformative approaches such as hiring and promoting more women to senior and leadership roles has been recommended widely to have positive downstream effects, as we observed in our finding that Nepali female senior researchers are more likely to support women in first authorship roles. ${ }^{40}$ Therefore, instead of hiring based on gender stereotypes or basing a worker's performance on the current definition of 'ideal worker' which is shaped by masculine norms, the organisation could reimagine the qualities of the 'ideal worker' by critically understanding the sociocultural barriers that women face, stopping exploitative approaches, and integrating both gender-accommodating and gender-transformative approaches. ${ }^{41}$ Similarly, conducting institution's gender analysis, promoting substantive equality principles such as affirmative mobilisation and fairness, putting in place special measures and enabling conditions to dismantle gendered disadvantages have also been recommended to help organisations become gender egalitarian and drive women's leadership. ${ }^{1}$

These findings are important not only at the organisational level but also to guide international collaborations, funding and publishing. Power imbalances can be seen in publications and funding in global health where priorities are often set by stakeholders at HICs who may 
not prioritise inclusion of women from LMICs. Our findings show that foreign male lead authors were not more likely than Nepali male lead authors to have female first authors. This highlights the need to support more women in research leadership positions by expanding programmes such as Athena Scientific Women's Scientific Network (SWAN) ${ }^{39}$ to academic and research institutions in LMICs: the Athena SWAN programme recognises and awards institutions pursuing gender equality in an array of organisational policies and indicators. The programme has shown greater and faster increase in female representations in UK institutions. ${ }^{42}$ Similarly, global mental health research funders could take gender equity indicators of organisations into account when selecting grant recipients. Journal publishers could also play a role in supporting female authorships by developing waiver systems for female authors from countries in the lower tiers of the Gender Inequality Index or Gender Development Index. Future research should evaluate of specific mitigation strategies and if and how they work to reduce gender barriers in the workplace, especially in LMICs. Our team is currently conducting a longitudinal social network analysis in Nepal to evaluate how mentoring and other forms of collaboration influence gender equity in academic productivity, as mediated by changes in selfefficacy and outcome expectations. ${ }^{43}$

\section{Limitations}

This study was only conducted with male and female staff based in Kathmandu, who may have a higher socioeconomic status, education level and greater access to resources when compared with staff living and working in rural areas of Nepal. However, based on prior gender research and experiences that our participants reported in rural communities, we can assume that the barriers that female staff face are even greater outside of urban areas. Experiences also may be different for women in Kathmandu with lower levels of education than our study participants. Our interviews are also structured within the male/female dichotomy and do not address the experiences and views of gender non-binary individuals. Nonbinary gender identity was not identifiable solely through names in authorship lists, and non-binary gender identity is not explicitly discussed at the organisational level in Nepal. Although the scoping review identified the lowest levels of representation were among ethnic minorities and members of low caste groups, we did not extensively explore the qualitative experiences of intersectionality (ie, gender by caste/ethnicity), nor the particular differences among castes and ethnicities in gender norms. Future research should explore intersectional stigma by gender and ethnicity from both the personal perspective and organisational policies. Our final limitation is that the study focused specifically on the field of mental and behavioural health, and the results may not be generalisable to other fields such as reproductive health or mental health researchers outside Nepal. However, our finding that Nepali women represent $38 \%$ of first author positions compared with $61 \%$ among Nepali men is consistent with the finding that women hold $37 \%$ of the key authorship positions across health research publications globally. ${ }^{12}$

\section{CONCLUSION}

This mixed-methods study combined a scoping review to explore the gender gap in research publications among Nepali mental health researchers with a qualitative study to further delineate the structural barriers that exacerbate the gender gap in health research in Nepal. Our findings from the scoping review shows disparities in authorship not just based on gender but also ethnicity. In-depth interviews revealed that there were wider structural discriminations within the organisations in areas of mobility, communication and networking, and work burden that restricted women's leadership and career development. Overall, what mattered to women were structures that fostered professional opportunities and growth without clashing with cultural norms. This, however, conflicts with what matter most to the organisation leadership that bases its structures around the traditional 'ideal worker' concepts. Reimagining the concept of the 'ideal worker' through transformative-and not merely accommodating-policies that consider what matters most to female researchers may foster gender equity and women's leadership in mental health research in Nepal.

Contributors DG, MS and PS created the qualitative tools, conducted interviews and coded the transcripts. AP and SM conducted the scoping review. DG, MS PS and BAK conceptualised the study and study design. All authors drafted and revised the manuscript. All authors have read and approved the final manuscript. $D G$ is responsible for the overall content as guarantor.

Funding DG, AP and BAK have received support from the US National Institutes of Health (R21MH111280 and R01MH120649, PI: BAK). AP has received support from the NIMH T32 on Social Determinants of HIV (T32MH128395-01).

Competing interests Some of the authors involved in this study were affiliated to the organisations included in the study.

Patient consent for publication Not applicable.

Ethics approval The study was approved by the National Health Research Council (NHRC), an ethical board in Kathmandu, Nepal. All qualitative study participants gave written consent prior to the study.

Provenance and peer review Not commissioned; externally peer reviewed.

Data availability statement Data are available on reasonable request. Data will be made available by authors upon reasonable request.

Supplemental material This content has been supplied by the author(s). It has not been vetted by BMJ Publishing Group Limited (BMJ) and may not have been peer-reviewed. Any opinions or recommendations discussed are solely those of the author(s) and are not endorsed by BMJ. BMJ disclaims all liability and responsibility arising from any reliance placed on the content. Where the content includes any translated material, BMJ does not warrant the accuracy and reliability of the translations (including but not limited to local regulations, clinical guidelines, terminology, drug names and drug dosages), and is not responsible for any error and/or omissions arising from translation and adaptation or otherwise.

Open access This is an open access article distributed in accordance with the Creative Commons Attribution Non Commercial (CC BY-NC 4.0) license, which permits others to distribute, remix, adapt, build upon this work non-commercially, and license their derivative works on different terms, provided the original work is properly cited, appropriate credit is given, any changes made indicated, and the use is non-commercial. See: http://creativecommons.org/licenses/by-nc/4.0/. 
ORCID iDs

Dristy Gurung http://orcid.org/0000-0003-1839-9382

Manaswi Sangraula http://orcid.org/0000-0003-0241-7945

Prasansa Subba http://orcid.org/0000-0002-6930-7575

Anubhuti Poudyal http://orcid.org/0000-0002-6426-2646

Brandon A Kohrt http://orcid.org/0000-0002-3829-4820

\section{REFERENCES}

1 Newman C, Chama PK, Mugisha M, et al. Reasons behind current gender imbalances in senior global health roles and the practice and policy changes that can catalyze organizational change. Glob Health Epidemiol Genom 2017;2:e19.

2 Dhatt R, Theobald S, Buzuzi S, et al. The role of women's leadership and gender equity in leadership and health system strengthening. Glob Health Epidemiol Genom 2017;2:E8.

3 Asi YM, Williams C. Equality through innovation: promoting women in the workplace in Low- and Middle-Income countries with health information technology. J Soc Issues 2020;76:721-43.

4 Downs JA, Mathad JS, Reif LK, et al. The ripple effect: why promoting female leadership in global health matters. Public Health Action 2016;6:210-1.

5 World Health Organization. Delivered by women, led by men: A gender and equity analysis of the global health and social workforce [Internet]. 2019. (Human Resources for Health Observer Series No. 24). Available: https://www.who.int/docs/default-source/nursing/ delivered-by-women-led-by-men.pdf?sfvrsn=94be9959_2

6 van Daalen KR, Bajnoczki C, Chowdhury M, et al. Symptoms of a broken system: the gender gaps in COVID-19 decision-making. BMJ Glob Health 2020;5:e003549.

7 Downs JA, Reif LK, Hokororo A, et al. Increasing women in leadership in global health. Acad Med 2014;89:1103-7.

8 Ribarovska AK, Hutchinson MR, Pittman QJ, et al. Gender inequality in publishing during the COVID-19 pandemic. Brain Behav Immun 2021;91:1-3.

9 Shah SGS, Dam R, Milano MJ, et al. Gender parity in scientific authorship in a national Institute for health research biomedical research centre: a bibliometric analysis. BMJ Open 2021:11:e037935.

10 Smith E, Hunt M, Master Z. Authorship ethics in global health research partnerships between researchers from low or middle income countries and high income countries. BMC Med Ethics 2014;15:42.

11 Larivière V, Ni C, Gingras Y, et al. Bibliometrics: global gender disparities in science. Nature 2013:504:211-3

12 Filardo G, da Graca B, Sass DM, et al. Trends and comparison of female first authorship in high impact medical journals: observational study (1994-2014). BMJ 2016;352:i847.

13 Pinho-Gomes A-C, Peters S, Thompson K, et al. Where are the women? gender inequalities in COVID-19 research authorship. BMJ Glob Health 2020;5:e002922.

14 Bali S, Dhatt R, Lal A, et al. Off the back burner: diverse and genderinclusive decision-making for COVID-19 response and recovery. BMJ Glob Health 2020;5:e002595.

15 Salem R, Yount KM. Structural accommodations of patriarchy: women and workplace gender segregation in Qatar. Gender Work Organ 2019;26:501-19.

16 Broderick NA, Casadevall A. Gender inequalities among authors who contributed equally. Elife 2019;8:e36399.

17 Ginther DK, Basner J, Jensen U, et al. Publications as predictors of racial and ethnic differences in $\mathrm{NIH}$ research awards. PLoS One 2018;13:e0205929.

18 United Nations Development Program. Human Development Report: Nepal [Internet], 2020. Available: http://hdr.undp.org/en/countries/ profiles/NPL
19 Acharya DR, Bell JS, Simkhada P, et al. Women's autonomy in household decision-making: a demographic study in Nepal. Reprod Health 2010;7:15.

20 Puri M, Tamang J, Shah I. Suffering in silence: consequences of sexual violence within marriage among young women in Nepal. BMC Public Health 2011;11:29.

21 Yamamoto Y, Matsumoto Ken'ichi, Matsumoto K. Choice of contraceptive methods by women's status: Evidence from largescale microdata in Nepal. Sexual \& Reproductive Healthcare 2017:14:48-54

22 Yamamoto Y, Matsumoto Ken'ichi, Kawata K, et al. Gender-Based differences in employment opportunities and wage distribution in Nepal. J Asian Econ 2019;64:101131.

23 Bushell B. Women entrepreneurs in Nepal: what prevents them from leading the sector? Gender \& Development 2008;16:549-64.

24 United Nations Development Program. Gender Development Index (GDI) [Internet], 2020. Available: http://hdr.undp.org/en/countries/ profiles/NPL

25 Central Bureau of Statistics. Report on the Nepal labour force survey 2017/18, 2019

26 Kohrt BA, Worthman CM. Gender and anxiety in Nepal: the role of social support, stressful life events, and structural violence. CNS Neurosci Ther 2009;15:237-48.

27 Adhikary JR. Barriers to career progression: a study of the perceptions of Nepali women employees. J. Bus. Mgt. Res. 2016;1:17-32.

28 Merriman R, Galizia I, Tanaka S, et al. The gender and geography of publishing: a review of sex/gender reporting and author representation in leading general medical and global health journals. BMJ Glob Health 2021;6:e005672.

29 Arksey H, O'Malley L. Scoping studies: towards a methodological framework. Int J Soc Res Methodol 2005;8:19-32.

30 Corp IBM. Ibm SPSS statistics for windows. Armonk, NY: IBM Corp, 2020.

31 Sandelowski M, Barroso J. Classifying the findings in qualitative studies. Qual Health Res 2003;13:905-23.

32 Castleberry A. NVivo 10 [software program]. Version 10. QSR International; 2012. Am J Pharm Educ 2014;78:25.

33 Hopkins AL, Jawitz JW, McCarty C, et al. Disparities in publication patterns by gender, race and ethnicity based on a survey of a random sample of authors. Scientometrics 2013;96:515-34

34 Yang LH, Chen F-P, Sia KJ, et al. "What matters most:" a cultural mechanism moderating structural vulnerability and moral experience of mental illness stigma. Soc Sci Med 2014;103:84-93.

35 Hay K, McDougal L, Percival V, et al. Disrupting gender norms in health systems: making the case for change. Lancet 2019;393:2535-49.

36 Interagency gender working group. Gender Integration Continuum [Internet]. Available: https://www.igwg.org/about-igwg/\#continuum [Accessed 03 Feb 2021]

37 Wade ME. Women and salary negotiation: the costs of SelfAdvocacy. Psychol Women Q 2001;25:65-76.

38 Dobbin F, Kalev A. Why Doesn't Diversity Training Work? The Challenge for Industry and Academia. Anthropology Now 2018;10:48-55.

39 Rosser SV, Barnard S, Carnes M, et al. Athena Swan and advance: effectiveness and lessons learned. Lancet 2019;393:604-8.

40 OECD. Policies and Practices to Promote Women in Leadership Roles in the Private Sector [Internet], 2020. Available: https://www. oecd.org/corporate/OECD-G20-EMPOWER-Women-Leadership.pdf

41 Kelly EL, Ammons SK, Chermack K, et al. Gendered challenge, gendered response. Gender \& Society 2010;24:281-303.

42 Xiao Y, Pinkney E, Au TKF, et al. Athena Swan and gender diversity: a UK-based retrospective cohort study. BMJ Open 2020;10:e032915.

43 Poudyal A, Gurung D, Kohrt BA. Evidence-Based approaches for promoting gender equity in global mental health research: study protocol for social network analysis of researchers in Nepal. SSM Ment Health 2021;1:100032. 